\title{
A Morphometric Study on the Nutrient Foramen of Metatarsal Bones in the Jharkhand Population
}

\author{
Kumari Sandhya ${ }^{1}$, K.K.P Singh ${ }^{2}$ \\ (Department Of Anatomy, Rajendra Institute Of Medical Sciences, Ranchi, India) ${ }^{l}$ \\ (Department Of Anatomy, Rajendra Institute Of Medical Sciences, Ranchi, India) ${ }^{2}$
}

\begin{abstract}
A total of 142 metatarsal bones of unknown age and sex were examined for the length of the bone and number \& position of the nutrient foramen. Study also included the direction of nutrient foramina and it's distances from both the ends. It was observed that almost all the Metatarsals had one nutrient foramen in the middle third of their shaft In $5^{\text {th }}$ Metatarsals majority of foramina were situated on the medial surface whereas in other metatarsals the foramen were mostly situated on the lateral surface. Invariably all foramina were directed away from the growing ends of the bone
\end{abstract}

Keywords: metatarsal, nutrient foramen, nutrient vessel, short long bone

\section{Introduction}

The metatarsals are the miniature long bones present in the foot and possess a head distally, a shaft and a base proximally (Standring 2005) ${ }^{[1]}$. The first metatarsal bone is large, strong and participates in supporting the weight of the body. The fifth metatarsal has a prominent tubercle on its base easily palpable along the lateral border of the foot, gives attachment to the peroneus brevis tendon (Snail 2007) ${ }^{[2]}$. The metatarsals have a single epiphysis at one end only (Patake \& Mysorekar 1977) ${ }^{[3]}$ as opposed to other long bones which do have it at both the ends . The, epiphyses appear for the base of the first metatarsal and for the heads in the remaining metatarsals (Patake \& Mysorekar 1977) ${ }^{[3]}$. The Metatarsal bones are frequently used in minimally invasive surgeries and osteotomies for construction of "Split Metatarsal musculo-osseous flap", in the reconstruction surgery of foot.. When a bone graft is taken, the vascularization of the remaining bones has also to be considered. The vascularity of this area allows various options in grafting ${ }^{[4]}$. It was reported that the ideal bone graft for the free transfer should include endosteal and periosteal blood supply with good anastomosis (Taylor $1979)^{[5]}$. The bony defect, appearing followed by different surgical procedures i.e. tumor resection, trauma repair or pseudoarthrosis needs to be reconstructed by bone grafting procedures. And the the best bone graft is supposed to be free vascularized bone graft (Pho RWH 1988) ${ }^{[6]}$ To prevent complications such as avascular necrosis during the design of minimally invasive surgeries (MIS) carried out on the toe of the foot it is important to know the position of the nutrient foramen in the metatarsal shaft .The nutrient artery of the metatarsal bone is very important during its active growth period as it is the main source of blood. Being the source of nutritional supply it plays an important role in fracture healing and union also (Shrimankar et al. 2010) ${ }^{[7]}$. The nutrient artery enters the metatarsal bone through nutrient foramen.

The topographical knowledge of these foramina in such operative procedures helps in preserving the circulation specially in free vascularized bone grafts, so that the osteoblasts can survive (Green 1988) ${ }^{[8]}$.. The knowledge about nutrient foramina is important in surgical procedures like utilization of metatarsal bones in the foot reconstruction. Singh (1960) ${ }^{[9]}$, while studying the variations in the articular facets of metatarsal bones, made some observations on their nutrient foramina. The nutrient foramina of long bones has been studied by many authors (Collipal et al. 2007; Kizilkanat et al. 2007 ${ }^{[10]}$; Murlimanju et al. 2011 $1^{[11]}$; Prashanth et al. $\left.2011^{[12]}\right)$, but the studies on the nutrient foramina in metatarsals are very few.

The directions of the nutrient canals are remarkably constant as it has been explained by different workers in different time period. Where Havers $(1691)^{[13]}$ described the directions of the nutrient canals in the long bones of Various mammals, Berard $(1835)^{[16]}$ correlated the direction of this canal with the mode of ossification and growth of the bone. Clark (1965) explained the obliquity of entrance of nutrient artery into the long bone related with Greater longitudinal growth at the growing end of a bone , and stated that nutrient artery was initially at right angles to the shaft, at its entrance and became oblique later on because of the the deflexion of nutrient artery towards the non-growing end of the bone. Aim of the present investigation was to study the morphometric anatomy of the nutrient foramina in human adult metatarsal bones which included it's number, location and distance from both ends of bone and whether the nutrient foramina do obey the general rule, i.e. directed away from the growing end. The foramina indexes for the metatarsal 1 bones were also determined to provide a mathematical method for accurately locating it prior to surgery 


\section{Material And Method}

144 bones available in department of anatomy in Rajendra Institute Of Medical Sciences, were included in the study. Damaged or bone with any pathology were excluded from the study Foramina for the nutrient artery were identified at first macroscopically and then with the help of magnifying lens on the shaft of all the metatarsal bones . An elastic rubber band was applied around these foramina for easy finding during process of measurements. The bones were photographed with the digital camera. Each bone was divided into three equal parts longitudinally and was analyzed topographically. Position of the nutrient foramina in relation to Surface of metacarpal bones were noted. Length of metatarsal bone and distance of foramen from its base were measured with help of slide calipers. Where two foramina were present, confirmation of primary foramen was done with help of very thin iron wire. Foramina index were calculated using Hughes formula.

$F I=(d / l) \times 100$

Where FI stands for foramen index, $\mathrm{d}$ stands for distance of foramen from base and 1 stands for length of bone Statistical analysis of indices was done and data were pooled in a tabular fashion

\section{Observation And Result}

In our study $100 \%$ of the $1^{\text {st }}$ metatarsal bones showed the presence of nutrient foramina on lateral surface table I. Out of 39 foramina found in 37 first metatarsal bones studied, 38 foramina were found in middle third whereas one foramen was found on proximal third, and 2 foramina were found in distal third. The mean value of Foramen index for nutrient foramen of first metatarsal bones was found to be $48.29( \pm 1.39)$ with range of ( 32.78-71.15) and SD 8.46 Table II.

In the $2^{\text {nd }}$ metatarsal bones $89 \%$ foramina were found on the lateral surface whereas 11 foramina were found on Planter ridge table I.. Out of 29 foramina found, in 29 second metatarsal bones studied, 26 foramina were found in middle third whereas 3 foramina were found on proximal third. The mean value of Foramen index for nutrient foramen of second metatarsal bones was found to be $43.68( \pm 1.78)$ with a range of $(17.91$ 63.33) and SD 9.58 Table II.

Table I Topographic Location Of Nutrient Foramina in relation to surface

\begin{tabular}{|c|c|c|c|c|c|c|c|c|c|}
\hline $\begin{array}{l}\text { Name of } \\
\text { Metatarsal } \\
\text { bone }\end{array}$ & $\begin{array}{l}\text { No of } \\
\text { foramina }\end{array}$ & $\begin{array}{l}\text { Right sided } \\
\text { bone }\end{array}$ & $\begin{array}{l}\text { Left sided } \\
\text { bone }\end{array}$ & $\begin{array}{l}\text { Me } \\
\text { sur } \\
\text { No }\end{array}$ & & $\begin{array}{l}\text { Late } \\
\text { surf } \\
\text { No }\end{array}$ & & \multicolumn{2}{|c|}{$\begin{array}{l}\text { Planter Ridge } \\
\text { No } \%\end{array}$} \\
\hline $\mathrm{I}^{\text {st }}$ Metatarsal & 39 & 12 & 17 & 0 & 0 & 39 & 100 & 0 & 0 \\
\hline II $^{\text {nd }}$ Metatarsal & 29 & 14 & 15 & 0 & 0 & 26 & 89 & 3 & 11 \\
\hline III $^{\text {rd }}$ Metatarsal & 24 & 12 & 12 & 0 & 0 & 24 & 100 & 0 & 0 \\
\hline IV $^{\text {th }}$ Metatarsal & 25 & 12 & 13 & 10 & 40 & 15 & 60 & 0 & 0 \\
\hline $\mathrm{V}^{\text {th }}$ Metatarsal & 27 & 13 & 14 & 20 & 74 & 07 & 26 & 0 & 0 \\
\hline
\end{tabular}

The $3^{\text {rd }}$ metatarsal bones showed their nutrient foramina located $100 \%$ on the lateral surface of bone. (table I). Out of 24 foramina found in 24 third metatarsal bones studied, 22 foramina were found in middle third whereas one foramen was found on distal third and one in the proximal third. The mean value of Foramen index for nutrient foramen of third metatarsal bones was found as $40.67( \pm 1.23)$ with the range of 29.57-56.89 and SD 6.03 (Table II). $40 \%$ of nutrient foramina in $4^{\text {th }}$ metatarsal bones were found to be located on medial surface whereas $60 \%$ were located on lateral surface (table I). Out of 25 foramina found in 25 fourth metatarsal bones studied, 19 foramina were found in the middle third while 6 foramina were located in the proximal third. Foramen index was found to be in the range of 30.76-63.33 with a mean of $40.5 \pm 1.65$ and SD 8.25 (Table II.)

Table II

Location of foramina in relation to distance from base and it's statistical analysis

\begin{tabular}{|l|l|l|l|l|l|l|l|l|l|}
\hline $\begin{array}{l}\text { Name of } \\
\text { Metatarsal }\end{array}$ & $\begin{array}{l}\text { Foramina } \\
\text { found in } \\
\text { Proximal } \\
\text { Third }\end{array}$ & $\begin{array}{l}\text { Foramina } \\
\text { found in } \\
\text { Middle } \\
\text { Third }\end{array}$ & $\begin{array}{l}\text { Foramina } \\
\text { found in } \\
\text { Distal Third }\end{array}$ & $\begin{array}{l}\text { Total } \\
\text { number of } \\
\text { Foramina } \\
\text { Found }\end{array}$ & $\begin{array}{l}\text { Range } \\
\text { Foramina } \\
\text { Index }\end{array}$ & Mean & SD & $\begin{array}{l}\text { SE } \\
\text { of } \\
\text { variation }\end{array}$ \\
\hline $\mathrm{I}^{\text {st }}$ Metatarsal & 00 & 38 & 01 & 39 & $32.78-71.15$ & 48.29 & 8.46 & 1.39 & $17.52 \%$ \\
\hline II $^{\text {metatarsal }}$ & 03 & 26 & 00 & 29 & $17.91-63.33$ & 43.68 & 9.58 & 1.78 & 21.93 \\
\hline III $^{\text {rd }}$ Metatarsal & 02 & 22 & 00 & 24 & $29.57-56.89$ & 40.67 & 6.03 & 1.23 & 14.83 \\
\hline $\begin{array}{l}\text { IV } \\
\text { Metatarsal }\end{array}$ & 06 & 19 & 00 & 25 & $30.76-63.33$ & 40.5 & 8.25 & 1.65 & 19.41 \\
\hline$V^{\text {th }}$ Metatarsal & 05 & 22 & 00 & 27 & $14.28-49.18$ & 37.37 & 8.24 & 1.59 & 22.05 \\
\hline
\end{tabular}


$74 \%$ of the nutrient foramina of $5^{\text {th }}$ metatarsal bones studied were found on medial surface whereas $26 \%$ of nutrient foramina were found on lateral surface of the bones table I. Out of of 27 foramina found in 27 fifth metatarsal bones studied, 22 foramina were found in middle third whereas 05 foramina were found on proximal third. The mean value of Foramen index for nutrient foramen of fifth metatarsal bones was found to be 37.37 \pm 1.59 with the range of $14.28-49.18$ and SD 8.24 (Table II.)

\section{Discussion}

In the present series of study only $5.4 \%$ of $1^{\text {st }}$ metatarsal bones showed double nutrient foramina though Anamika et al $(2015)^{[16]}$ in their study, found it to be of $22.2 \%$ first metatarsals as having dual foramina .Singh (1960) $)^{[17]}$ found two foramina most commonly in the first and fifth metatarsals. However, in the Patake series two foramina were seen most frequently in the first metatarsal. The topographical information of nutrient foramen could be required in few surgeries (Malukar \& Joshi 2011) ${ }^{[18]}$. It has been stated that the vessels, which occupy the nutrient foramen, are derived from those which took part in the invasion of ossifying cartilage, so that the nutrient foramen is at the site of original center of ossification (Payton 1934) ${ }^{[19]}$. During the growth there is slanting of the nutrient canal because of the higher longitudinal development at the growing end. The directions of nutrient foramina of all long bones are always way from the growing end (Malukar \& Joshi 2011) ${ }^{[18]}$.. It is evident that most metatarsals have one nutrient foramen located in the middle third of bone (Patake \& Mysorekar 1977) ${ }^{[19]}$. They also reported that the double foramina were seen most frequently in the first metatarsal. Our study showed agreement with these observation as we also found double nutrient foramen in $1^{\text {st }}$ metatarsal only Out of of 39 foramina found in 37 first metatarsal bones studied, 38 foramina were found in middle third whereas one foramen was found on proximal third, and 2 foramina were found in distal third. The mean value of Foramen index for nutrient foramen of first metatarsal bones was found to be $48.29( \pm 1.39)$ with range of (32.78-71.15) and SD 8.46 whereas study of Anamika $k$ et al(2015) ${ }^{[16]}$ showed FI as having Mean value of as F.I. 65.3 . Coff var was found as $17.52 \%$.

In our study $100 \%$ of the $1^{\text {st }}$ metatarsal bones showed the presence of nutrient foramina on lateral surface whereas in Anamika et al(2015) ${ }^{[16]}$ study the foramina were on the lateral surface in 41 metatarsals and over the plantar ridge in 11 cases. The foramina were not observed on the medial surface of any of the first metatarsal bone. The detailed analysis of the foramina of the first metatarsal bone is represented in Table 1 . In the $2^{\text {nd }}$ metatarsal bones $89 \%$ foramina were found on the lateral surface whereas 11 foramina were found on Planter ridge. In Anamika et al(2015) ${ }^{[16]}$ study the foramen was present at the medial surface in 12 cases, at the lateral surface in 32 and over the plantar ridge in $2^{\text {nd }}$ second metatarsals. Out of 29 foramina found, in 29 second metatarsal bones studied, in our series, 26 foramina were found in middle third whereas 3 foramina were found on proximal third. The mean value of Foramen index for nutrient foramen of second metatarsal bones was found to be $43.68( \pm 1.78)$ with a range of (17.91-63.33) and SD. 9.58. Anamika k et al(2015) ${ }^{[16]}$ showed FI as Mean having 43.6 .

In Department of Surgery, Central Defense Hospital. Madrid, Spain a study was conducted by S. Ramírez Varela and his colleagues (2007) on $3^{\text {rd }}$ metatarsal bones and proximal phalanges of third toe. They proposed a predictive equation based on the distance of the NF from the base of both bones and their total lengths. The $3^{\text {rd }}$ metatarsal bones in our study showed their nutrient foramina located $100 \%$ on the lateral surface of bone. In Anamika et al(2015) ${ }^{[16]}$ study it was observed at the medial surface in 29 cases, at lateral surface in 14 metatarsals and at the plantar ridge in four cases. Out of of 24 foramina found in 24 third metatarsal bones studied in present series, 22 foramina were found in middle third whereas one foramen was found on distal third and one in the proximal third. The mean value of Foramen index for nutrient foramen of third metatarsal bones was found as $40.67( \pm 1.23)$ with the range of 29.57-56.89 and SD 6.03 . Anamika k et al $(2015)^{[16]}$ showed FI as having the Mean value of FI as 44.4. Cof of variation was found to be 14.83 which suggests that in case of $3^{\text {rd }}$ metatarsal bones predictive equation can be given for toe metatarsal grafts. $40 \%$ of nutrient foramina in $4^{\text {th }}$ metatarsal bones were found to be located on medial surface whereas $60 \%$ were located on lateral surface in our study. Anamika et al(2015) ${ }^{[16]}$ showed 31 on medial surface 21 lateral surface and 1 on plantar ridge . Patake and Mysorekar (1977) ${ }^{[20]}$ and Singh (1960) ${ }^{[17]}$ observed that, in the fourth metatarsal, foramina were more commonly observed on the medial surface. Out of 25 foramina found in 25 fourth metatarsal bones studied, 19 foramina were found in the middle third while 6 foramina were located in the proximal third in the present series. Foramen index was found to be in the range of 30.76-63.33 with a mean of $40.5 \pm 1.65$ and SD 8.25. Anamika $\mathrm{k}$ et al(2015) ${ }^{[16]}$ showed FI as having mean value of 45.3 .

Topography of the nutrient artery in the fifth metatarsal bone is important while planning a corrective osteotomy for a bunionette deformity. This would allow the most proximal osteotomy possible without interrupting the nutrient arterial supply (McKeon et al. 2013) ${ }^{[21]}$. They described the nutrient artery and studied the topography of the nutrient foramen of the fifth metatarsal bone. In our study $100 \%$ fifth metatarsal bones showed single nutrient foramen though Singh $(1960)^{[17]}$ found two foramina in fifth metatarsals. In our series of 
study $74 \%$ of the nutrient foramina of $5^{\text {th }}$ metatarsal bones studied were found on medial surface whereas $26 \%$ of nutrient foramina were found on lateral surface of the bones. Anamika et al(2015) ${ }^{[16]}$ showed 8 foramina on medial surface no foramen on lateral surface and 17 foramen on plantar ridge. Out of of 27 foramina found in 27 fifth metatarsal bones studied in present series, 22 foramina were found in middle third whereas 05 foramina were found on proximal third. The mean value of Foramen index for nutrient foramen of fifth metatarsal bones was found to be $37.37 \pm 1.59$ with the range of $14.28-49.18$ and SD 8.24.Anamika k et al(2015) ${ }^{[16]}$ showed FI as having the Mean value of. 47.5 .

\section{Conclusion}

The information can be of use for plastic surgeons in designing vascularized bone graft for reconstruction surgeries of foot from the metatarsal bones.

\section{Reference}

[1]. Standring, S. 2005. Gray’s Anatomy. The anatomical basis of clinical practice. 39th edition. Edinburgh: Elsevier, Churchill Livingstone; 1520-2. Wood Jones, F. 1946. Buchanan's Manual of Anatomy. London: Bailliere, Tindall and Cox; $310,367$.

[2]. Snell, R.S. 2007. Clinical Anatomy by Systems. Baltimore: Lippincott Williams and Wilkins; 358.

[3]. Patake, S.M., Mysorekar, V.R. 1977. Diaphysial nutrient foramina in human metacarpals and metatarsals. J Anat 124(Pt 2): 299304.

[4]. Menck J, Döbler A, Döhler JR, Vaskularisation des Humerus, Langenbeck's Arch Surg, 1997, $382(3): 123-127$.

[5]. Taylor GI, Fibular transplantation. In: Serafin D, Bunke HJ (eds), Microsurgical composite tissue transplantation, C.V. Mosby Co., St. Louis, 1979, 418-423.

[6]. Pho RWH, Microsurgical technique in orthopaedics, $1^{\text {st }}$ edition, Butterworth \& Co. Ltd., Scotland, 1988,128

[7]. Shrimankar, D.P.S., Trivedi, D.J., Kariya, V.B. 2010. A study of nutrient foramina of the metacarpal bones. NJIRM 1(2): 16-21.

[8]. Green, D.P. 1988. Operative hand surgery. 2nd edition. New York: Churchill Livingstone; 1248

[9]. Singh, I. 1960. Variations in the metatarsal bones. J Anat 94: 345-50.

[10]. Kizilkanat, E., Boyan, N., Ozsahin, E.T., Soames, R., Oguz, O. 2007. Location, number and clinical significance of nutrient foramina in human long bones. Ann Anat 189(1): 87-95.

[11]. Murlimanju, B.V., Prashanth, K.U., Prabhu, L.V., Saralaya, V.V., Pai, M.M., Rai, R. 2011. Morphological and topographical anatomy of nutrient foramina in human upper limb long bones and their surgical importance. Rom J Morphol Embryol 52(3): 85962.

[12]. Prashanth, K.U., Murlimanju, B.V., Prabhu, L.V., Kumar, C.G., Pai, M.M., Dhananjaya, K.V.N. 2011. Morphological and topographical anatomy of nutrient foramina in the lower limb long bones and its clinical importance. Australas Med J 4(10): 5307.

[13]. Havers .C(1691):In Osteologia Nova or some new observations of the bone ,London,Quoted by Lutken vide infra

[14]. Berard (1835):Arch Gener, de Med,II Ser 7 176-183 Quoted by Lutken vide infra

[15]. Pho, R.W.H. 1988. Microsurgical technique in orthopaedics. 1st edition. Scotland: Butterworth \& Co. Ltd; 128.

[16]. Anamika k. Abhishek PS, Anujj, Murlimanju BV, Divya P, Latha VP, Vasudha VS, Chitra PR, Ashwin RR, Teresa J, Prashanth KU 2015 Morphology of Nutrient Foramina in Human Metatarsals and Their Clinical Importance; Med \& Health 10(1): 37-47

[17]. Singh, I. 1960. Variations in the metatarsal bones. J Anat 94: 345-50.

[18]. Malukar, O., Joshi, H. 2011. Diaphysial nutrient foramina in long bones and miniature long bones. NJIRM 2(2): 23-6.

[19]. Payton, C.G. 1934. The position of the nutrient foramen and direction of the nutrient canal in the long bones of the madder-fed pig. J Anat 68(Pt 4): 500-10. Pho, R.W.H. 1988. Microsurgical technique in orthopaedics. 1st edition. Scotland: Butterworth \& Co. Ltd; 128.

[20]. Patake, S.M., Mysorekar, V.R. 1977. Diaphysial nutrient foramina in human metacarpals and metatarsals. J Anat 124(Pt 2): 299304.

[21]. McKeon, K.E., Johnson, J.E., McCormick, J.J., Klein, S.E. 2013. The intraosseous and extraosseous vascular supply of the fifth metatarsal: implications for fifth metatarsal osteotomy. Foot Ankle Int 34(1): 117-23 